\title{
Two cases of chronic pancreatitis associated with anomalous pancreaticobiliary ductal union and SPINK1 mutation
}

\author{
Eun Sam Rho, MD', Earl Kim, MD', Hong Koh, MD', Han-Wook Yoo, MD², Beom Hee Lee, MDD, , Gu-Hwan Kim, MD ${ }^{2}$ \\ 'Department of Pediatrics, Severance Children's Hospital, Yonsei University College of Medicine, Seoul \\ ${ }^{2}$ Department of Pediatrics, ${ }^{3}$ Medical Genetics Center, Asan Medical Center Children's Hospital, University of Ulsan College of Medicine, Seoul, Korea
}

Chronic pancreatitis is a progressive inflammatory disease resulting from repeated episodes of acute pancreatitis that impair exocrine function and eventually produce endocrine insufficiency. Some causes of chronic pancreatitis appear to be associated with alterations in the serine-protease inhibitor, Kazal type 1 (SPINK1), cationic trypsinogen (PRSS1), and cystic fibrosis-transmembrane conductance regulator (CFTR) genes, or with structural disorders in the pancreaticobiliary ductal system, such as pancreatic divisum or anomalous pancreaticobiliary ductal union (APBDU). However, it is unusual to observe both genetic alteration and structural anomaly. Here, we report 2 cases with both APBDU and a mutation in the SPINK1 genes, and we discuss the implications of these findings in clinical practice.

Key words: Chronic pancreatitis, Anomalous pancreaticobiliary ductal union, Serine protease inhibitor, Kazal type 1

\section{Introduction}

Chronic pancreatitis (CP) is a progressive inflammatory disease, initiated by repeated episodes of acute pancreatitis, that results in impairment of exocrine and eventually endocrine insufficiency ${ }^{1,2)}$. In spite of careful analysis, it can be difficult to determine the causes of the disease and sometimes a genetic study is useful. Some researchers observe that serine protease inhibitor, Kazal type 1 (SPINK1), cationic trypsinogen (PRSS1) or cystic fibrosis transmembrane conductance regulator (CFTR) genes are pancreatitis susceptibility genes and individuals who have these genes rapidly progress to $\mathrm{CP}^{1,3-5)}$.

Anomalous pancreaticobiliary ductal union (APBDU) is a disorder in which the junctional union between the common bile duct (CBD) and the pancreatic duct outside the duodenal wall has an abnormal position beyond the influence of the sphincter of $0 \mathrm{ddi}^{6}$. In this pathologic condition, reflux of pancreatic juice into the biliary tract system occurs because of the lack of Oddi's sphincter function ${ }^{7)}$. It is frequently associated with various pancreaticobiliary diseases, including choledochal cyst, bile duct cancer, gallbladder cancer, gallbladder adenomyomatosis, pancreatitis, and pancreas divisum ${ }^{6,7)}$. Pancreas divisum is also a well known cause of acute recurrent pancreatitis ${ }^{8)}$.

We report two cases with APBDU with CP. After surgical or endoscopic sphincterotomy (EST) treatment for APBDU, both patients had pancreatitis relapses. And eventually both patients revealed to have a genetic mutation of SPINK1 gene. We discuss the implications of the findings with the controversial issues of anatomical defects of the pancreas such as APBDU with genetic mutation in the context of $\mathrm{CP}$.
Corresponding author: Hong Koh, MD Department of Pediatrics, Severance Children's Hospital, Yonsei University College of Medicine, 50 Yonsei-ro, Seodaemun-gu, Seoul 120-752, Korea Tel: +82-2-2228-2050

Fax: +82-2-393-9118

E-mail: khong@yuhs.ac

Received: 8 December, 2011

Revised: 17 April, 2012

Accepted: 2 August, 2012
Copyright (C 2013 by The Korean Pediatric Society

This is an open-access article distributed under the terms of the Creative Commons Attribution NonCommercial License (http://creativecommons.org/ licenses/by-nc/3.0/) which permits unrestricted noncommercial use, distribution, and reproduction in any medium, provided the original work is properly cited. 


\section{Case report}

\section{Case 1}

A 2 year 8 month old girl presented with intermittent severe right upper abdominal pain for six days. In spite of fasting and conservative care, her pain remained. Choledochal cyst was

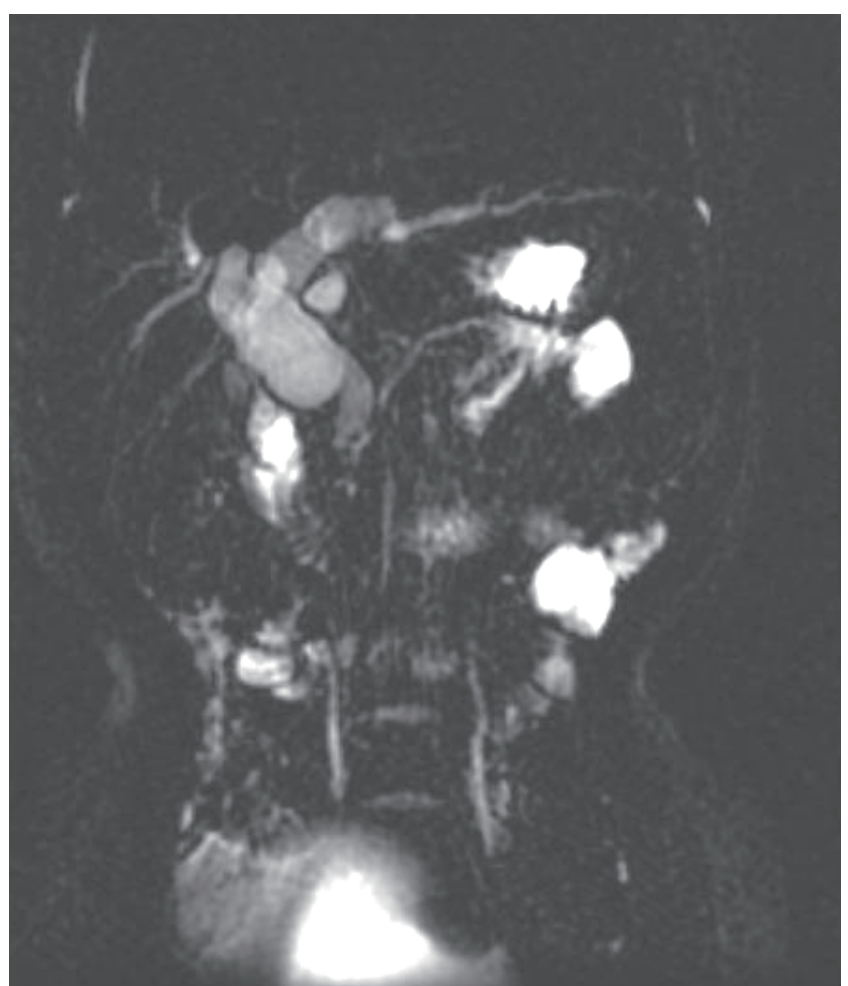

Fig. 1. Magnetic resonance cholangiopancreatography revealed a choledochal cyst (type IVa) with anomalous pancreaticobiliary ductal union (P-C type) and bile sludge in the common bile duct and common channel. found in ultrasonography. She was referred to our hospital for further evaluation and management of choledochal cyst. Magnetic resonance cholangiopancreatography (MRCP) showed a choledochal cyst (type IVa) with APBDU (P-C type) and bile sludge in the CBD and common channel (Fig. 1). Hepaticojejunostomy with jejunostomy and excision of choledochal cyst was performed. At the routine checkup two years later, blood test results of serum amylase and lipase levels were $210 \mathrm{U} / \mathrm{L}$ and $125 \mathrm{U} / \mathrm{L}$. MRCP was done again which showed focal dilatation of the upstream pancreatic duct and pancreatic duct stone. Endoscopic retrograde cholangiopancreatography (ERCP) was performed and the pancreatic duct stone was removed (Fig. 2). To evaluate the etiology of CP, screening tests including infection and autoimmune disorders were performed and a genetic study was done. Genetic testing revealed mutations in CP: p.N34S mutation in the SPINK1 gene (Fig. 3A).

\section{Case 2}

A 4 year 6 month old girl with five days of periumbilical abdominal pain and vomiting visited a local clinic. An initial workup which was remarkable for elevated amylase and lipase $(1,135 \mathrm{U} / \mathrm{L}$ and 2,950 U/L, respectively) confirmed the diagnosis of acute pancreatitis. She was brought to Severance Children's Hospital for further evaluation of pancreatitis. After conservative care for fifteen days, blood test results showed normal levels of amylase and lipase. After five days of normalization, abdominal pain recurred. Amylase and lipase were re-elevated (251 U/L and 1,259 U/L, respectively). The abdominal pain prompted a comprehensive evaluation for $\mathrm{CP}$. MRCP demonstrated pancreatitis with pancreas swelling and pancreatic duct dilatation. Ectopic insertion of CBD and ventral pancreatic duct and pancreatic divisum was seen (Fig. 4). ERCP was performed and EST of major papilla and minor papilla was done instead of operation. ERCP

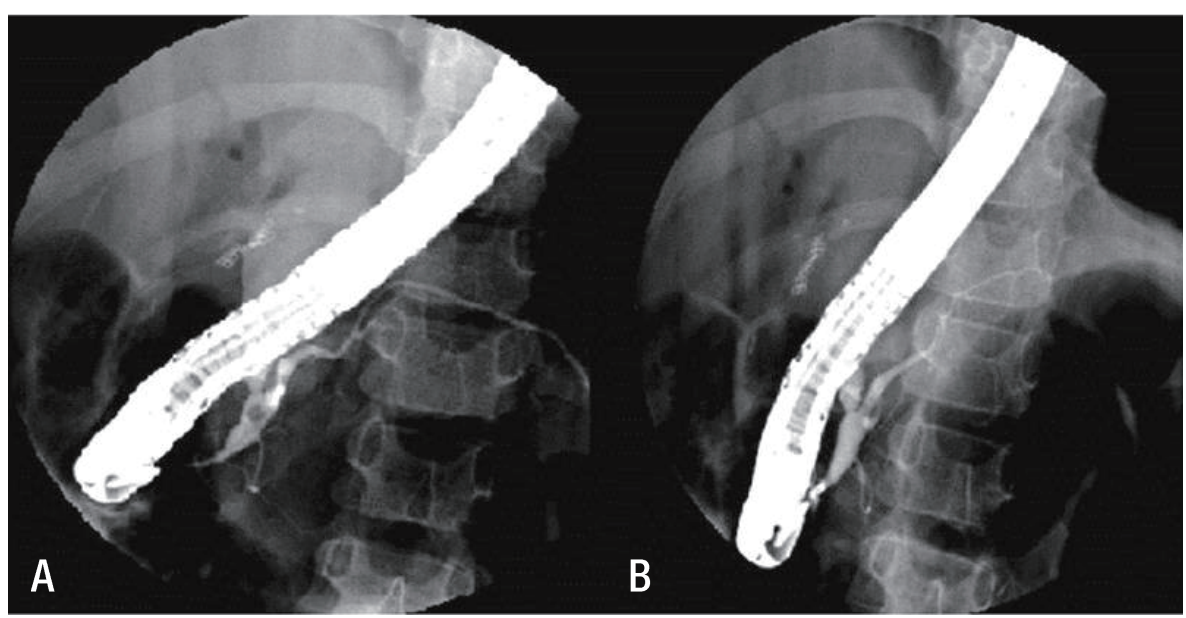

Fig. 2. Endoscopic retrograde cholangiopancreatography showed focal dilatation of the upstream pancreatic duct and a pancreatic duct stone (A). Pancreatic duct after stone removal (B). 


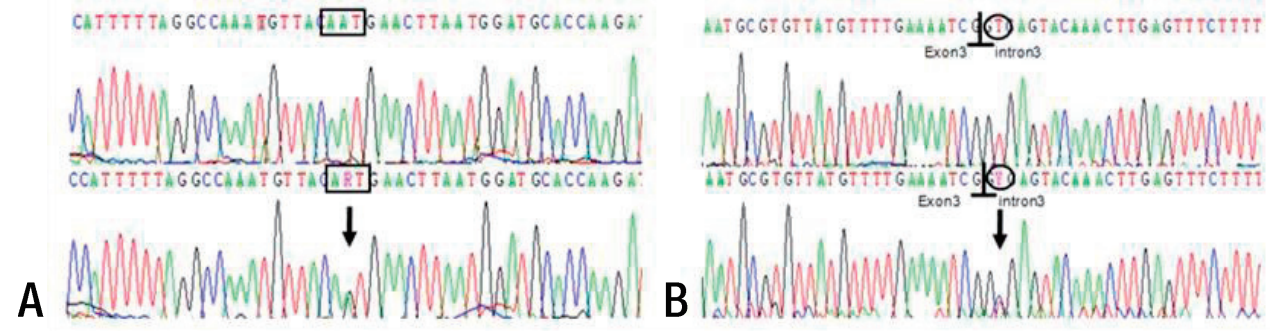

Fig. 3. Partial DNA sequence of SPINK1, located on 5q32, with the heterozygote c.104A $>\mathrm{G}$ (p.Asn34Ser) mutation in exon 3 of SPINK1. The 3 nucleotides for coding the amino acid are marked in the box (A). The c.194+2T>C, intron 3-splicing donor-site mutation is marked in the open circle with the exon-intron boundary signs (B). Upper panel: normal electrogram; lower panel: patient's electrogram. Sites of heterozygote mutation are indicated with arrows. $\mathrm{R}$, heterozygote of nucleotides $\mathrm{A}$ and $\mathrm{G} ; \mathrm{Y}$, nucleotides $\mathrm{T}$ and $\mathrm{C}$.

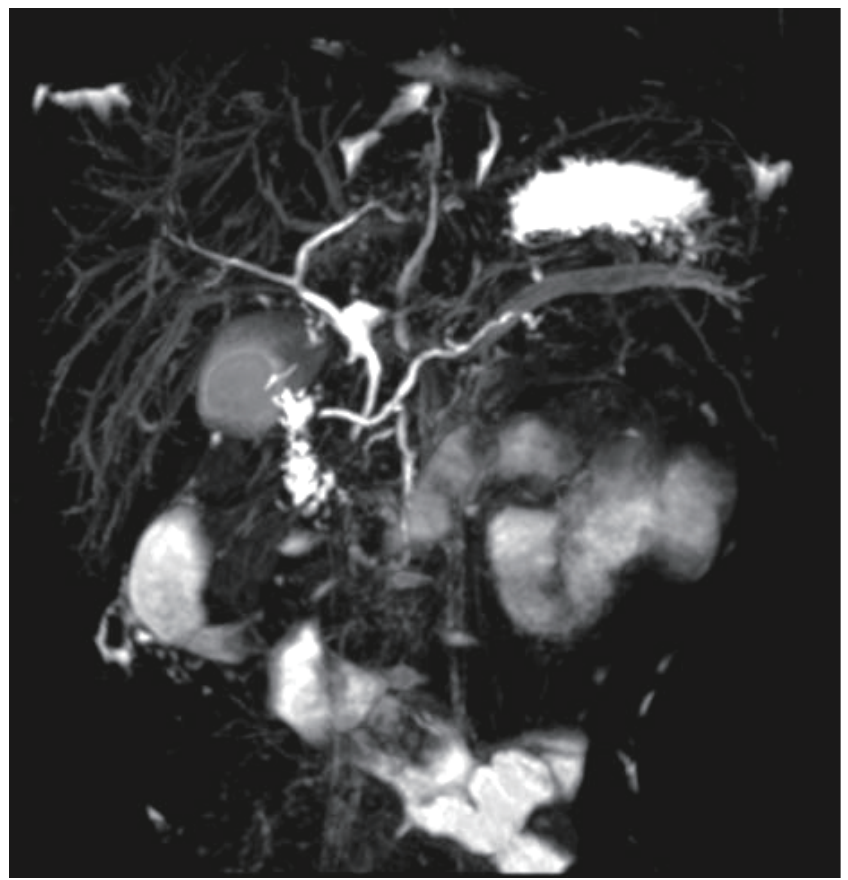

Fig. 4. Magnetic resonance cholangiopancreatography revealed pancreatic divisum and swelling of pancreas with ductal dilatation. The dorsal main pancreatic duct connect to the minor papilla and the ventral pancreatic duct joined the common bile duct (CBD) and drained into the major papilla (ectopic insertion of CBD and ventral pancreatic duct). The major papilla is seen at the junction of the second and third parts of the duodenum.

demonstrated incomplete pancreas divisum and APBDU. The major papilla of the duodenum was not remarkable. Selective deep cannulation of the bile duct was done successfully and the sphincterotomy was performed with pull type sphincterotome. On the cholangiography obtained by the major papilla selective cannulation, the bile duct was observed to have no dilation or obstruction. However, the main pancreatic duct was visualized just $1.5 \mathrm{~cm}$ distal to the ampulla and joined with CBD. On the minor papilla, the minor pancreatic duct was communicated to the body and tail of the pancreas with dilation. After two months of EST, MRCP was done again and demonstrated a decreased caliber of the dorsal pancreatic duct and no remarkable changes of CBD, intrahepatic duct, or ventral pancreatic duct. Pancreatic enzymes were checked in an outpatient clinic and the enzyme levels presented in a wax and wane pattern. Genetic testing revealed SPINK1 IVS3+2T>C splicing mutations (Fig. 3B).

\section{Discussion}

The known causes of pancreatitis in children are trauma, drug toxicity, infection, metabolic disorders, anatomic defects, hereditary pancreatitis, and vascular disease ${ }^{9)}$. In recent studies pancreatitis-associated susceptibility genes were detected ${ }^{3)}$. PRSS1 gene cause hereditary pancreatitis, CFTR mutation are associated with idiopathic CP and SPNIK1 are associated with $\mathrm{CP}^{1,3,4,5}$. SPINK1 mutations are more common than PRSS1 mutations in patients with acute recurrent pancreatitis or $\mathrm{CP}^{10)}$. On SPINK1 mutation, p.N34S and IVS3 $+2 \mathrm{~T}>\mathrm{C}$ mutations are most frequently observed ${ }^{10-12)}$.

There are reports of pancreas divisum associated with $\mathrm{CP}$ with SPINK1 mutation ${ }^{10}$. CP associated with APBDU, combined with SPINK1 mutation has not previously reported. In this report, one case had a choledochal cyst (type IVa) with APBDU and had surgical treatment. The other case has an incomplete pancreas divisum with APBDU and had an endoscopic therapeutic intervention. After the procedure, even though the anatomical correction was done, both patients had recurrent pancreatitis and were diagnosed with CP.

If functional and structural abnormalities of the pancreas surface are coexisted, the final diagnosis of chronic recurrent pancreatitis is often made only several years after the first occurrence of pancreatitis with laboratory studies and imaging ${ }^{133}$. Until now, genetic testing in CP patients has not been part of any standard diagnostic procedure. Criteria for PRSS1 and SPINK1 mutation testing are controversial but include: recurrent acute pancreatitis with a family history of $\mathrm{CP}, \mathrm{CP}$ without another etiology with or without a positive family history after ruling 
out other causes for pancreatitis, or unexplained pancreatitis in children ${ }^{14)}$. In this cases, PRSS1 and SPINK1 mutation testing was done because $\mathrm{CP}$ occurred after anatomical correction, and both patient had SPINK1 mutation.

SPINK1 is a potent protease inhibitor which prevents premature intrapancreatic activation of trypsin and pancreatic autodigestion and act as a protector. Studies described strong associations of SPINK1 mutation and different forms of pancreatitis $^{13,15)}$, but SPINK1 mutation alone is incapable of initiating pancreatitis and cause $\mathrm{CP}^{10,15)}$. This mutation acts as a diseasemodifier or plays a role within polygenic or multifactorial models ${ }^{1,12,15)}$. Mutations in the SPINK1 gene have been reported to lower the threshold for pancreatitis in the presence of other genetic or environmental factors and acts as a disease-modifier ${ }^{4,10,15)}$.

An anatomic defect may be an incidental finding or a contributing factor in pancreatitis. Deliberating the possibility of combined diseases is important due to plausible relations of acute pancreatitis, choledochal cyst and gall bladder cancer in APBDU patients. Especially those combined with pancreatitis, complications and its association with APBDU seems to lead to more risks. In patients with APBDU, surgical correction of such a defect remains controversial but it may alleviate symptoms and prevent further damage to the pancreas from recurrent attacks of pancreatitis $^{9)}$.

Therefore, studies for gene mutation as a disease-modifier are needed if pancreatitis does occur secondarily to an anatomic defect, even if anatomically correction of the pancreatic ductal system was done.

\section{Conflict of interest}

No potential conflict of interest relevant to this article was reported.

\section{References}

1. Schneider A. Serine protease inhibitor Kazal type 1 mutations and pancreatitis. Clin Lab Med 2005;25:61-78.
2. Ota Y, Masamune A, Inui K, Kume K, Shimosegawa T, Kikuyama M. Phenotypic variability of the homozygous IVS3+2T>C mutation in the serine protease inhibitor Kazal type 1 (SPINK1) gene in patients with chronic pancreatitis. Tohoku J Exp Med 2010;221: 197-201.

3. Morinville V, Whitcomb DC. Recurrent acute and chronic pancreatitis: complex disorders with a genetic basis. Gastroenterol Hepatol 2005; 1:195-205.

4. Schneider A, Barmada MM, Slivka A, Martin JA, Whitcomb DC. Clinical characterization of patients with idiopathic chronic pancreatitis and SPINK1 mutations. Scand J Gastroenterol 2004;39: 903-4.

5. Liddle RA. Pathophysiology of SPINK mutations in pancreatic development and disease. Endocrinol Metab Clin North Am 2006; 35:345-56.

6. Katsinelos P, Dimiropoulos S, Katsiba D, Galanis I, Pilpilidis I, Tsolkas $\mathrm{P}$, et al. Acute recurrent pancreatitis associated with anomalous pancreaticobiliary ductal union and choledochal cyst of mixed type I plus II. Surg Endosc 2003;17:162.

7. Shimotake T, Aoi S, Tomiyama H, Iwai N. DPC-4 (Smad-4) and $\mathrm{K}$-ras gene mutations in biliary tract epithelium in children with anomalous pancreaticobiliary ductal union. J Pediatr Surg 2003;38: 694-7.

8. Park JB, Seo JH, Park JY, Park SW, Song SY, Chung JB, et al. Endoscopic treatment of a pediatric patient with acute pancreatitis caused by anomalous union of pancreaticobiliary duct combined with incomplete pancreatic divisum. Korean J Gastroenterol 2009;54:333-6.

9. Muzaffar AR, Moyer MS, Dobbins J, Cahow CE, Gryboski JD, Shneider BL. Pancreas divisum in a family with hereditary pancreatitis. J Clin Gastroenterol 1996;22:16-20.

10. Lee YJ, Kim KM, Choi JH, Lee BH, Kim GH, Yoo HW. High incidence of PRSS1 and SPINK1 mutations in Korean children with acute recurrent and chronic pancreatitis. J Pediatr Gastroenterol Nutr 2011;52:478-81.

11. Truninger K, Witt H, Kock J, Kage A, Seifert B, Ammann RW, et al. Mutations of the serine protease inhibitor, Kazal type 1 gene, in patients with idiopathic chronic pancreatitis. Am J Gastroenterol 2002;97:1133-7.

12. Drenth JP, te Morsche R, Jansen JB. Mutations in serine protease inhibitor Kazal type 1 are strongly associated with chronic pancreatitis. Gut 2002;50:687-92.

13. Derikx MH, Drenth JP. Genetic factors in chronic pancreatitis; implications for diagnosis, management and prognosis. Best Pract Res Clin Gastroenterol 2010;24:251-70.

14. Rosendahl J, Bodeker H, Mossner J, Teich N. Hereditary chronic pancreatitis. Orphanet J Rare Dis 2007;2:1.

15. Oh HC, Lee TY, Kwon S, Lee SS, Seo DW, Lee SK, et al. SPINK1 N34S mutation as a possible cause of chronic pancreatitis in a patient with familial background. Korean J Gastroenterol 2007;49:384-9. 